\title{
GERMINAÇÃO E CRESCIMENTO DE ESPÉCIES DE MARACUJÁ ${ }^{1}$
}

\author{
ADELISE DE ALMEIDA LIMA², RANULFO CORRÊA CALDAS², VANDERLEI DA SILVA SANTOS²
}

RESUMO - Objetivou-se, neste trabalho, avaliar a germinação e o índice de velocidade de emergência de cinco espécies de maracujazeiro para obtenção de plantas aptas ao processo de enxertia. O experimento foi conduzido em casa de vegetação da Embrapa Mandioca e Fruticultura Tropical, em Cruz das Almas (BA), no período de janeiro a junho de 2002. Foi utilizado o delineamento experimental inteiramente casualizado, e os tratamentos foram constituídos de: Passiflora edulis Sims f. flavicarpa Deg., Passiflora edulis Sims, Passiflora giberti N.E. Brown, Passiflora laurifolia L. e Passilfora alata Curtis, com quatro repetições e 25 plantas por parcela. As espécies constituíram cinco grupos diferentes para a variável índice de velocidade de emergência. No tocante à germinação, foram identificados dois grupos diferentes, um formado pelas espécies $P$. giberti e P. laurifolia e o outro, pelas demais espécies. Em termos de altura de planta, a espécie $P$. giberti apresentou a maior média, $40,40 \mathrm{~cm}$, constituindo um grupo que é diferente das demais. As espécies $P$. edulis e $P$. edulis f. flavicarpa apresentaram melhores índices de velocidades de emergência e germinação e, conseqüentemente, as plantas obtidas mostraram-se aptas ao processo de enxertia em menor período de tempo.

Termos para indexação: Propagação vegetativa, índice de velocidade de emergência, enxertia.

\section{GERMINATION AND GROWTH OF PASSION FRUIT SPECIES}

ABSTRACT - This work aimed to verify the germination and speed of emergence index of passion fruit species to obtain plants suitable for grafting. The experiment was carried out in a greenhouse at Embrapa Cassava and Tropical Fruits, in Cruz das Almas, BA from January to June, 2002. It was used a completely randomized design and the treatments were constituted of five passion fruit species: Passiflora edulis Sims f. flavicarpa Deg., Passiflora edulis Sims, Passiflora giberti N.E. Brown, Passiflora laurifolia L. and Passiflora alata Curtis, with four replications. The species constitute five different groups for the variable, speed of emergence index and, concerning to the germination, two different groups, one formed by the species P. giberti and P. laurifolia and the other by the species P. edulis Sims f. flavicarpa, P. edulis Sims and P. alata. Regarding to plant height, the species $P$. giberti had the highest average, $40,40 \mathrm{~cm}$, constituting a group that is different from the others. The species $P$. edulis and $P$. edulis $\mathrm{f}$. flavicarpa presented better speed of emergence index and germination, consequently the plants obtained were ready for grafting in a shorter period of time.

Index terms: asexual propagation, speed rate of emergence, grafting.

Apesar da importante posição do Brasil como líder mundial na produção de maracujá, a produtividade brasileira é das mais baixas, estimada em 10 t/ha. Como os pomares de maracujá, em sua totalidade, são estabelecidos com mudas obtidas de sementes, a elevada heterozigose existente nesta espécie determina uma alta variabilidade, resultando em desuniformidade entre plantas nos pomares. A propagação vegetativa por meio da técnica da enxertia apresenta vantagens na manutenção das boas características agronômicas, favorecendo a multiplicação de plantas produtivas e tolerantes a pragas e doenças. Estas vantagens permitem a implantação de pomares tecnicamente superiores àqueles formados por meio de plantas obtidas a partir de sementes.

Para se desenvolver um trabalho de propagação vegetativa, por meio da enxertia, é necessário que se conheçam o índice de velocidade de emergência e o tempo necessário para produção de mudas das diferentes espécies. Na literatura se dispõe de poucas informações sobre velocidade de emergência e tempo para produção de mudas de outras espécies comestíveis de maracujazeiro que não sejam o amarelo e o roxo. São José \& Nakagawa (1987), comparando o efeito da fermentação nas sementes com e sem arilo de maracujá-amarelo (Passiflora edulis Sims. f. flavicarpa Deg.), constataram diferenças significativas no índice de velocidade de emergência. As sementes com arilo, quando submetidas à fermentação, tiveram sua qualidade prejudicada, em relação àquelas sem arilo.

Estudando os efeitos de métodos de extração de sementes e de ácido giberélico na qualidade de sementes de maracujá-doce (Passiflora alata), Coneglian et al. (2000) observaram que as sementes submetidas aos métodos de extração apresentaram maior porcentagem e velocidade de emergência após a pré-embebição em substrato umedecido com solução a $300 \mathrm{mg} / \mathrm{L}$ de $\mathrm{GA}_{3}$.

Ferreira et al. (2001), estudando a germinação de sementes de P. alata (maracujá-doce), submetidas a diferentes tempos de embebição e concentração de ácido giberélico, verificaram que elevadas concentrações são benéficas para aumentar a velocidade de emergência das sementes destas espécies. Assim, recomendaram a concentração de $500 \mathrm{mg} / \mathrm{L}$.

Objetivou-se, neste trabalho, avaliar o índice de velocidade de emergência e a germinação de cinco espécies de maracujazeiro para obtenção de plantas aptas ao processo de enxertia.

O experimento foi realizado em casa de vegetação da Embrapa Mandioca e Fruticultura Tropical, em Cruz das Almas (BA), no período de janeiro a junho de 2002. Foi utilizado o delineamento experimental inteiramente casualizado, com cinco tratamentos repetidos quatro vezes, com 25 plantas por parcela. Os tratamentos foram constituídos de cinco espécies de maracujazeiro: Passiflora edulis Sims f. flavicarpa Deg., Passiflora edulis Sims, Passiflora giberti N.E. Brown, Passiflora laurifolia L. e Passiflora alata Curtis.

As sementes foram obtidas de frutos maduros colhidos na mesma data, no Banco Ativo de Germoplasma (BAG) da Embrapa Mandioca e Fruticultura Tropical.

Após a coleta, os frutos foram seccionados transversalmente e as sementes foram extraídas com despolpador, o qual retirou a mucilagem sem danificá-las. A seguir, elas foram colocadas sobre uma peneira e lavadas com jatos de água de torneira e, posteriormente, colocadas em papel de filtro para secar à sombra e semeadas imediatamente.

Foram distribuídas quatro sementes por recipiente; posteriormente, quando as mudas atingiram $5 \mathrm{~cm}$ de altura, efetuou-se o desbaste, deixando-se a mais vigorosa. Empregaram-se sacos de polietileno de $15 \mathrm{~cm}$ de largura x $20 \mathrm{~cm}$ de comprimento, contendo substrato esterilizado, composto pela mistura de terriço e esterco de curral na proporção de 3:1, em câmara úmida (cobertura plástica). Foram feitas irrigações diárias.

As variáveis avaliadas foram: germinação, índice de velocidade de emergência, tempo (dias) para a obtenção das mudas, altura de plantas, massa da matéria seca da raiz, da parte aérea e total.

A germinação foi avaliada aos 14 dias após a semeadura pela porcentagem de plântulas emergidas e, para medir o índice de velocidade de emergência, foram efetuadas contagens com intervalos de três dias,

\footnotetext{
${ }^{1}$ (Trabalho 105/2005). Recebido: 29/04/2005. Aceito para publicação: 20/02/2006.

${ }^{2}$ Pesquisadore da Embrapa Mandioca e Fruticultura Tropical, Caixa Postal, 007, CEP 44380-000, Cruz das Almas-BA. E-mail: adelise@cnpmf.embrapa.br.
} 
TABELA 1 - Médias de Índice de Velocidade de Emergência - IVE e Germinação - G de cinco espécies de maracujazeiro. Cruz das Almas-BA, 2002.

\begin{tabular}{ccc}
\hline Tratamento & Índice de velocidade de emergência (IVE) (em dias) & Germinação (G) $(\%)$ \\
\hline Passiflora giberti & $16,10 \mathrm{c}$ & $72,0 \mathrm{~b}$ \\
P. edulis f. flavicarpa & $8,85 \mathrm{e}$ & $95,0 \mathrm{a}$ \\
P. edulis & $9,08 \mathrm{~d}$ & $100,0 \mathrm{a}$ \\
P. alata & $20,15 \mathrm{~b}$ & $100,0 \mathrm{a}$ \\
P. laurifolia & $26,43 \mathrm{a}$ & $79,0 \mathrm{~b}$ \\
\hline C. V. (\%) & 6,19 & 6,49
\end{tabular}

Médias com a mesma letra fazem parte do mesmo agrupamento pelo, teste de Scott-Knot, a 5\% de probabilidade.

TABELA 2 - Médias de altura da planta, massa da matéria seca total, matéria seca da parte aérea e matéria seca da raiz de cinco espécies de maracujazeiro. Cruz das Almas-BA, 2002.

\begin{tabular}{|c|c|c|c|c|}
\hline \multirow[t]{2}{*}{ Tratamento } & \multirow[t]{2}{*}{ Altura $(\mathrm{cm})$} & \multicolumn{3}{|c|}{ Massa da matéria seca } \\
\hline & & Total $(\mathrm{g})$ & Aérea $(\%)$ & Raiz (\%) \\
\hline Passiflora giberti & $40,40 \mathrm{a}$ & $2,04 \mathrm{a}$ & $92,00 \mathrm{a}$ & $8,00 \mathrm{e}$ \\
\hline P.edulis f. flavicarpa & $22,18 \mathrm{~b}$ & $1,44 \mathrm{~b}$ & $84,22 \mathrm{~b}$ & $15,78 \mathrm{~d}$ \\
\hline P. edulis & $22,03 \mathrm{~b}$ & $1,50 \mathrm{~b}$ & $78,07 \mathrm{~d}$ & $21,93 \mathrm{~b}$ \\
\hline P. alata & $18,83 \mathrm{~b}$ & $1,37 \mathrm{~b}$ & $81,07 \mathrm{c}$ & $18,93 \mathrm{c}$ \\
\hline P. laurifolia & $17,53 \mathrm{~b}$ & $0,90 \mathrm{c}$ & $60,66 \mathrm{e}$ & 39,34 a \\
\hline C. V. $(\%)$ & 12,05 & 38,70 & 7,70 & 18,55 \\
\hline
\end{tabular}

Médias com a mesma letra fazem parte do mesmo agrupamento, pelo teste de Scott-Knot, a 5\% de probabilidade.

a partir do início da emergência até a sua estabilização. Foi considerada como emergida, a plântula que apresentava as folhas cotiledonares abertas. No momento em que as mudas estavam aptas para serem enxertadas, foram avaliadas a altura, medindo-se do colo da plântula até a gema apical, além da massa da matéria seca da parte aérea, da raiz e total, após manutenção em estufa a $75^{\circ} \mathrm{C}$, com circulação forçada de ar, até atingirem massa constante (Cardoso et al., 2001).

$\mathrm{O}$ índice de velocidade de emergência foi determinado utilizando-se da fórmula de Edmond \& Drapala (1958):

$I=\frac{\left(N_{1} G_{1}\right)+\left(N_{2} G_{2}\right)+\ldots . .+\left(N_{n} G_{n}\right)}{\left(G_{1}+G_{2}+\ldots . .+G_{n}\right)}$

onde:

$\mathrm{N}_{1}=$ número de dias para a primeira contagem;

$\mathrm{G}_{2}=$ número de plântulas emergidas na primeira contagem;

$\mathrm{N}_{2}=$ número de dias para a segunda contagem;

$\mathrm{G}_{2}=$ número de plântulas emergidas na segunda contagem;

$\mathrm{N}_{\mathrm{n}}=$ número de dias para a última contagem;

$\mathrm{G}_{\mathrm{n}}=$ número de plântulas emergidas na última contagem.

Os dados obtidos foram submetidos à análise de variância, e as médias estimadas foram agrupadas pelo teste de Scott-Knott, a 5\% de probabilidade. Os dados da massa da matéria seca da parte aérea e da raiz foram expressos em porcentagem da massa da matéria seca total da planta.

As médias das variáveis índice de velocidade de emergência IVE e germinação - G encontram-se na Tabela 1.

Segundo o teste de Scott-Knott, as espécies constituíram cinco grupos diferentes para a variável índice de velocidade de emergência - IVE, sendo a espécie $P$. edulis f. flavicarpa a de maior velocidade e $P$. laurifolia a mais lenta. Estes resultados estão de acordo com os obtidos por Lima et al. (1997) que, avaliando porta-enxertos e tipos de enxertia para o maracujá-amarelo, verificaram ser necessário semear as espécies $P$. alata e $P$. caerulea 15 dias antes que $P$. giberti e $P$. foetida, que por sua vez devem ser semeadas 15 dias antes que $P$. edulis Sims f. flavicarpa e P. cincinnata.

No tocante à germinação, foram identificados dois grupos, um formado pelas espécies $P$. giberti e P. laurifolia e o outro, pelas espécies $P$. edulis Sims f. flavicarpa, $P$. edulis Sims e P. alata (Tabela 1). São José (1987), estudando os efeitos de dois ambientes distintos de armazenamento (condições naturais e refrigeração) sobre a germinação de sementes de maracujá-amarelo, verificou que a velocidade de emergência foi significativamente superior para as sementes armazenadas em condições de ambiente natural. Duarte Filho et al. (1998), em trabalho realizado com o objetivo de avaliar a germinação de sementes de Passiflora giberti, sob efeito de diferentes temperaturas, concluíram que a maioria das sementes germinaram 14 dias após a semeadura.

Em termos de altura de plantas, a espécie $P$. giberti apresentou a maior média, $40,4 \mathrm{~cm}$, constituindo um conjunto que é diferente do grupo das demais, cuja média variou de 22,18 a 17,53 cm. Em função da existência de correlação positiva entre a altura da planta e massa da matéria seca total, a espécie $P$. giberti apresentou a maior média, para estas variáveis, formando um grupo diferente daqueles constituídos pelas outras espécies (Tabela 2).

As espécies $P$. edulis e $P$. edulis f. flavicarpa apresentaram melhores índices de velocidade de emergência e germinação e, conseqüentemente, as plantas obtidas mostraram-se aptas ao processo de enxertia em menor período de tempo.

\section{REFERÊNCIAS}

CARDOSO, G. D.; TAVARES, J. C.; FERREIRA, R. L. F.; CÂMARA, F. A. A.; CARMO, G. A. do. Desenvolvimento de mudas de maracujazeiroamarelo obtidas de sementes extraídas por fermentação. Revista Brasileira de Fruticultura, Jaboticabal, v. 23, n. 3, p. 639-642, dez. 2001.

CONEGliAn, R. C. C.; ROSSETO, C. A. V.; SHIMIZU, M. K.; VASCONCELLOS, M. A. da S. Efeitos de métodos de extração e de ácido giberélico na qualidade de sementes de maracujá-doce (Passiflora alata Dryand). Revista Brasileira de Fruticultura, Jaboticabal, v. 22, n. 3, p. 463-467, dez. 2000.

DUARTE FILHO, J.; VASCONCELLOS, M. A. da S.; CARVALHO, C. M. Germinação de sementes de Passiflora giberti N. E. Brow sob temperatura controlada. In: SIMPÓSIO BRASILEIRO SOBRE A CULTURA DO MARACUJAZEIRO, 5., 1998, Jaboticabal. Anais... Jaboticabal: FUNEP, 1998. p.315-316.

EDMOND, J. B.; DRAPALA, W. J. The effects of temperature, sand and soil, and acetone on germination of okra seed. Proceedings of the American Society Horticutural Science, Alexandria, n. 71, p. 428434, 1958

FERREIRA, G.; FOGAÇA, L. A.; MORO, E. Germinação de sementes de Passiflora alata Dryander (maracujá-doce) submetidas a diferentes tempos de embebição e concentrações de ácido giberélico. Revista Brasileira de Fruticultura, Jaboticabal, v. 23, n. 1, p. 160-163, abri. 2001. 
LIMA, A. de A.; SANTOS FILHO, H. P.; CALDAS, R. C. Porta-enxertos e tipos de enxertia para o maracujá-amarelo. Cruz das Almas-BA: EMBRAPA-CNPMF, 1997.3p. (Comunicado Técnico, 50).

SÃO JOSÉ, A. R. Influência do método de extração na qualidade fisiológica de sementes de maracujazeiro-amarelo (Passiflora edulis Sims. f. Flavicarpa). 1987. Tese (Dissertação de Mestrado) - Faculdade de Ciências Agronômicas, Universidade Estadual de Botucatu, Botucatu, 1987.
SÃO JOSÉ, A. R.; NAKAGAWA, J. Influência do método de extração na qualidade fisiológica de sementes de maracujazeiro-amarelo. In: CONGRESSO BRASILEIRO DE FRUTICULTURA, 6., 1987, Campinas. Anais... Campinas: SBF, 1987. v.2, p. 619-623. 